\title{
Value of Children Within the Families in Iran: An Asian Perspective
}

\author{
Mohammad Taghi Sheykhi* \\ Professor Emeritus of Sociology, Alzahra University, Iran
}

*Corresponding author: Mohammad Taghi Sheykhi, Professor Emeritus of Sociology, Alzahra University, Iran

\begin{abstract}
The paper mainly explores the attitudes and perceptions of the families towards the value of children; optimistically as a source of happiness. Families invest on their children from cradle to grave as much as they can. The process of modernization in different dimensions is creating various controversies which require new and appropriate policies to solve the emerging problems. The value of children within the families in Iran originates in their socio-economic values in different dimensions to the parents. However, children are prone to prospering or suffering depending on the statues of families with special reference to the status of their mothers. Because of the obvious difference in the attitudes, values and life parents of people and families form different cultures and way of life, the perceptions of positive and negative values of children would differ from one culture to another and from one region to another. The method of research used in the present work is of qualitative type.

Aims

It is argued that we need to consider the family as a controversial issue because of the differences between ideology of the family, and the reality of the variety of various ways in which men, women, boys and girls, live together and interact. The paper aims to explore how families changed in the past half century, why people marry, and/or have children, and how synergy and solidarity in the family are achieved. The scope and scale of happiness in the family in terms of values [1], and whether the family is in a state of crisis are also investigated. Providing answers to such questions and many more, are some of the aims of the paper. The paper will reflect a synthesis of families in the ever-changing world with special reference to Tehran, Similarly, Iran's current state of children and families need such investigation in terms of economic, social and cultural perspectives. Analysis of the dynamics of families in society is also a part of the aims of the paper.
\end{abstract}

Keywords: Value of Children; Attitudes; Perceptions; Controversies; Policies

\section{Introduction}

In Iran, high fertility rates have swelled the proportions of children and young people, which has contributed to the emergence of complicated and controversial problems. In Iran, where about a third of population is at age of $0-14$, who enter and pass through the youth course with increasing needs and expectations, such a survey on youth is very necessary. Despite the high numbers of children, until recently, they received little attention from academics and policymakers; a situation that has begun to change over the past two decades. Many sociologists and historians have long argued that children in earlier times (before 1800) were economically essential to their parents and families, which is no longer the case at present Gittins [2]. Undoubtedly children have been and continue to have an economic value ally. In many cases in the past children often started contributing to the family economy from ages of 3 or 4 years onwards. Within the poorest sectors of modern society, even today, a child's contribution to the family can still be crucial. "Nowadays", the unpaid domestic labour of girls in many families much in the past, was important economically. "In many families", yet, the price of producing children was also a high one in earlier times; children frequently resulted in the mother's death, and often that of the child, and this could cause an acute economic crisis in the family. High mortality constantly threatened a family's labour supply. Despite all these challenges, having children also contributes to cultural transmission, [2] brings status to the family, and in particular for the women in Iran, and as a whole in many Third World societies. That is, they contribute to human capital, potential support for the families etc. Having children creates new power relationships; between mother and child, between father 
and child, and between parents. Having children also empowers mother according to the Iranian culture. Until recently, and even today, many parents have had (have) real fears about their old age. They want children to take care of them materially and emotionally when they are old. Children are known to be a source of love and emotional support to lonely and aged parents. Without children parents are afraid of a lonely, painful old age, and uncomforted death Dowrick [3]. It is now universally accepted that family size may affect individual development, and that there is a fundamental right to choose the size and spacing of the family Salas [4]. Based on modern values, state of existence that is deemed important, desirable and worth striving for, i.e. norms which are parts of the culture of a society Neubeck et al. [5] is so spreading among parents that future depends on more than the number of children in the family. Parents now realize that increasing the size of the family will decrease the quality of life of each child. However, as result of medical advances and social change, new standards are appearing within the Iranian families.

\section{Theoretical Perspectives}

As cons believe, children have widely been neglected in the social sciences until recently Prout and James [6]. The reason for that is based on the assumption that as children's lives are impermanent, they are unimportant Montgomery [7]; or because children or the youth need never be taken very seriously due to changing values Wulff [8]. However, it is important to note that studies of children or the youth have emerged from interdisciplinary areas. Lately, the areas of social science and sociobiology that dominated research with children was developmental psychology. That is, and area of the study of children that was initially conceived of as a way of finding solutions to their general psychological problems rather than be concerned specifically with children or even child development Jenks [9]. Educationists who were concerned with children as recipients of schooling, seldom delved further into children's lives. In recent years; in the 1990s, sociologists began to recognize children as legitimate subject of study. However, because of increasing trends of urbanization, and the resultant sociocultural change, children and the youth became very vulnerable and thence they became the subject of study of many social scientists. Currently, social scientists are cautious about describing any type of behaviour as instinctive. Even sociologists hold that children's behaviour is primarily guided by the surrounding culture. Of course, this does not mean that biology plays no part in children's behaviour. Human life, after all, depends on the functioning of the body. We also know that children share many biological traits with their parents, especially physical characteristics such as height, weight, hair, and eye color, and facial features. Intelligence and various personality characteristics have some genetic component. But whether a person develops an inherited potentiality or not, depends on the opportunities associated with the social position Goldsmith [10]. In a nutshell, the evidence shows that nurture/ care is far more important than nature in determining children's behaviour. By and large, we should not think of nature as opposing nurture. They are complementary to each other. For children therefore, nature and nurture are inseparable.

\section{Methodology}

The research methods used in the present paper for specific fact-finding, and operations to yield the required data, have been a mixed-method strategy of investigation. In the theoretical section, the author has referred to various relevant theories, approaches and literature reviews. In the empirical section, 250 family units comprising of 500 spouses of different backgrounds and localities were sampled in Tehran. Those men and women were interviewed orally. As qualitative research is becoming increasingly popular in the social sciences, interviews highly contribute towards clarifying issues. However, the interview method was used in this research mainly to discover something new through live communication. In conducting the research, the following techniques, tools, and procedures were employed

a) Books, documents and other relevant sources of information as secondary/documentary evidence.

b) Observation: the researcher used this method too, through visiting people and centres like nurseries to investigate issues affecting children and their families.

c) Interviews: interviews were mainly used to find ideas, probe responses, and investigate motives and feelings, which cannot be obtained through the use of questionnaires. This flexible method was used as a means to understand the variables associated with children as a source of happiness in the context of their families.

Table 1: Selected Interviewees/Couples by Age Groups and Number of Children.

\begin{tabular}{|c|c|c|c|}
\hline \multicolumn{2}{|c|}{$\begin{array}{c}\text { Number of } \\
\text { Interviewees }\end{array}$} & \multirow{2}{*}{$\begin{array}{c}\text { Age Groups } \\
30-69\end{array}$} & \multirow{2}{*}{$\begin{array}{c}\begin{array}{c}\text { Average No. of } \\
\text { Children }\end{array} \\
4.3\end{array}$} \\
\hline Total & 500 & & \\
\hline \multicolumn{2}{|c|}{100} & $30-34$ & 3.3 \\
\hline \multicolumn{2}{|c|}{90} & $35-39$ & 3.6 \\
\hline \multicolumn{2}{|c|}{70} & $40-44$ & 3.9 \\
\hline \multicolumn{2}{|c|}{62} & $45-49$ & 4.2 \\
\hline \multicolumn{2}{|c|}{58} & $50-54$ & 4.4 \\
\hline \multicolumn{2}{|c|}{50} & 55-59 & 4.9 \\
\hline \multicolumn{2}{|c|}{40} & $60-64$ & 5.1 \\
\hline \multicolumn{2}{|c|}{30} & $65-69$ & 5.3 \\
\hline
\end{tabular}

Relevant samples were selected in order to provide the necessary insights into the value or happiness of children in the Iranian society. In conducting the survey, 250 couples (500 men and Women) within the limits of the Province of Tehran were interviewed and the intended questions were investigated. Through this qualitative method, attitudes, ideas, feelings, views, and behaviour of the respondents were sought in order to assess the value of children. Conducting interviews provided the author with the opportunity to observe patterns of child-family interactions from very close quarters. Table1, [selected interviewees/couples by age group and number of children] indicates that younger couples tend to have smaller number of children on average. It may 
therefore be deduced that the value of children has declined among the younger generations.

\section{Familial influences}

The value of children as a source of happiness within the Iranian families originates in their socio-economic values in different dimensions to the parents. Research findings highlight the fundamental motivations for having children. So far as the author has acknowledged, the study reveals that children as a source of happiness to parents varies from culture to culture and according to the sex of the parents and children, and gender identity [4]. It is also important to find out how parents consciously weigh factors when they make decisions on family size. In addition, knowledge is needed about how parents' general psychological needs are transformed into needs for children, how values that are specific to children are formed and developed, and how the needs for children differ according to the number and sex composition of children already born. However, there is a close relationship between the well-being of the children, and that of their mothers, fathers' incomes, educational levels, and decisions to have children, extend family size etc. When women are empowered to live full and productive lives, children prosper. On the contrary, when women are denied equal opportunities within a society, children suffer. Though in most places in the developing world women earn less than men for equal work, income disparities between the sexes are less in Iran. Children tend to benefit more in situations where women make crucial decisions. Therefore, the consequences of women's exclusion from making key household decisions can be as dire for children as they are for women themselves. In families in which women are key decision-makers, the proportion of resources devoted to children is far greater than those in which women play a less decisive role. "This is so because women generally place a higher premium than men on welfare-related goals, and are more likely to use their influence and the resources they control, to promote the needs of children in particular, and those of the family in general" The State of World Children 2007 [11]. However, mothers' participation in the workforce can be beneficial to children, because it often results in women gaining greater access to, and control of, economic resources. But, paid employment for women does not automatically lead to better outcomes for children. Factors such as the amount of time women spend working outside the household, the conditions under which they are employed, and who controls the income they generate, all determine how their employment affects their own well-being and that of their children. Nonetheless, the demands of work also often leave parents with less time to spend with their children. They are often unable to devote quality time to their children without jeopardizing their ability to support their families. Working long hours can be problematic for low-income families, yet many employers do not regard workschedule flexibility to be an option for low-wage workers.

\section{Violence against Children}

Despite all forms of educational and socialization upheavals around the world, yet every year, as many as 275 million children worldwide become caught in the crossfire of domestic violence and suffer the full consequences of a turbulent home life [11]. Violence against children involves physical and psychological abuse and injury in different forms according to socio-cultural backgrounds, negligent treatment, exploitation, child labour, and even sexual abuse in some cases. The agents may include parents and other close family members. So far as the domestic violence against children in Iran is concerned, this phenomenon has highly decreased within the Iranian families in the past two decades because of educational and socialization promotion in younger families. It has been highly forbidden at schools too. Domestic violence is currently known as a negative value and anti-social behaviour within the families in particular in larger cities in Iran. Generally speaking, children who survive abuse, often suffer longterm physical and psychological damage that impairs their ability to learn and socialize and makes it difficult for them to perform well in school and develop close and positive friendships. Children who usually grow up in a violent home and in an atmosphere of family violence [5], are more likely to suffer abuse compared to children who have a peaceful home life. As searched, in some countries such as China, Egypt, Mexico and South Africa, there is a strong correlation between violence against women and violence against children [11]. However, the consequences of domestic violence can span generations. The effects of violent behaviour tend to stay with children long after they leave the childhood home. Boys who are exposed to their parents' domestic violence are twice as likely to become abusive men as are the sons of non-violent parents. Furthermore, girls who witness their mothers being abused, are more likely to accept violence in a marriage than girls who come from non-violent homes. Children may experience difficult circumstances for a number of reasons, but in most cases the root problem is an underlying context of acute vulnerability. In many cases, it is the livelihood strategies that particularly impoverished and vulnerable children and families employ that place children in specially difficult circumstances. These difficult circumstances are also often interrelated. As a result of war, for instance, children may be separated from their parents, live on the streets, etc. Those living on the streets are more vulnerable to being trafficked, being affected by AIDS, other diseases, and anti-social behaviour.

\section{Value of Children}

Due to the obvious differences in the attitudes, values and life patterns of people and families from different cultures, and ways of life, the perceptions of positive and negative values of children will differ from one culture to another, and from one region to another in Iran. Although the value of children can be conceptually regarded as a balance of two opposing forces, i.e. satisfactions and costs of children, in this paper the negative and positive dimensions of the value of children, i.e. their economic, social and psychological values are highly inter-related.

\section{Positive Values of children}

The values or aspects of happiness would include:

a) Economic and social benefits and security;

b) Emotional benefits; 
c) Self-enrichment and development;

d) Family cohesion and continuity; and

e) Identification with children;

\section{Negative Values of Children}

Parents must also be aware of the negative aspects of having children. The qualities which contribute to the unhappiness of the families are:
a) Economic and social costs;
b) Emotional costs;
c) Restrictions/opportunity costs;
d) Physical demands; and
e) Family costs;

\section{Economic and Social Benefits and Security}

Benefits and happiness could be derived from children's help in the house, business or on the farm, care of siblings, and from sharing of income, both when children are young and when they are grown up. Security is also an aspect of this value [12]. Middleclass respondents are generally not concerned about the economic benefits and security of having children. However, there is only one exception; sons are valued for their socio-economic benefits and security by the middle-class respondents. They are known as a source of happiness in the family.

\section{Emotional Benefits}

Happiness, love, companionship, and fun for the parents/ families are included in this category. Viewed in reverse, avoidance of loneliness and boredom can also be considered as emotional benefits. The emotional benefits of children do not relate only to one country, society or culture, but may be perceived as global. Such benefits as emphasized upon both by middle- and lower-class respondents as positive values. In spite of the emotional benefits of having children, nowadays, many children are emotionally abandoned especially among urban communities, and due to the abundance of children in the families Ginat [13]. They eventually become street children.

\section{Self- enrichment and Development}

This value consists of learning from the experience of raising children, becoming more mature and responsible, and being recognized as an adult, or a grown man or woman. Incentive in life as provided by children are also considered a value of selfenrichment. Middle-class respondents perceived children not only as providing emotional benefits, but also as enhancing the personal development of the parents [14].

\section{Family Cohesiveness and Continuity}

Throughout history human beings have generally preferred large families to small ones in order to ensure the survival of a particular family line or racial group. However, the situation has changed dramatically in the twentieth century Zgourides. This value (contribution) includes the benefits children provide in making a family more complete, and also in continuing the family name. It includes children as a bond between husband and wife, a fulfilment of marriage, and a competition of family life. That is an interaction which acts as a happiness multiplier in the family. However, the milieu and social conditions have determining impacts on the value system of having children, i.e. factors such as ethics, religion, literacy, science, knowledge, family traditions etc., Shamloo all which play part in creating happiness in the family [15].

\section{Identification with the Children}

This value is derived from the pleasure of watching the growth and development of children, pride in children's accomplishments and reflection of one's self in children. Similarly, given their socioeconomic setting, lower-class groups might feel that their only means of social mobility is through their children's success (JSS 2001:123). To many respondents, children may also be seen as important for performing social or religious functions. Such values include, having children to conform to social or religious norms, to benefit society, perform religious rituals, etc.

\section{Negative Values}

\section{Economic and Social Costs}

These costs include childbearing, educational and socialization costs of children. Due to the difference in economic settings of social classes, there appears to be different perceptions of economic and social costs of having children. Today, and while the costs of living is ever rising, urban people have become cautious and tend not to have many children. Therefore, they are now aware of the financial costs of having larger families.

\section{Emotional Costs}

General emotional strain, concern about discipline and moral behaviour of children, future of the occupational status of the children, health and general security of the children are some of the aspects which cause family anxieties so far as the value of the children in the Iranian families are concerned. So, many families are looking for desired family size. Thus, families wish to proceed according to the principle of: "every child a wanted child".

\section{Restrictions/Opportunity Costs}

These costs are derived from lack of flexibility and freedom in various aspects of life such as travel, social life, recreation, leisure activities etc. Lack of privacy and time for personal needs and desires are also included. Such lags and shortages are qualitatively and quantitatively increasing under the circumstances of social and economic change. Such restrictions are especially salient for the middle-class respondents as a disadvantage of having children as compared to having no children at all. The relative importance of this negative value diminishes however, due to reasons for not wanting another child; suggesting that opportunity costs are significant in the decision to have children, or not to have more children after the first child has been born to the family. However, such negative values are highly transparent in the modern times. 


\section{Physical Demands}

This category includes extra housework, loss of sleep, and general weariness in caring for children. Here, physical demands are not important to middle-class respondents expect in the context of wanting more than the desired amount of goods and services. In other words, lower-class people usually have a relatively large number of children since they are not able to hire help for the work on farm, etc. As a result, physical demands of children become a burden to them.

\section{Family Costs}

These costs consist of spending less with spouse's affection/ desire because of children or other kinds of negative effects on husband-wife relationship because of children. This negative value is considered somewhat important by respondents in all three socio-economic groups as a reason for not having another child. Similarly, to have or reach higher per capita income, wanting children must be revised and reconsidered. That is to say, more economic development and higher productivity are dependent on smaller family size (Croll 2000:22). Source: 2006 Word Population Data Sheet. Gross National Income Purchasing Power Parity Based on the figures reflected in Table 2 as compared with previous years, quantitative values of children in Iran have decreased significantly. Instead, with the decline in the numbers of children within the Iranian families, their qualitative values have increased.

Table 2: Demographic, Economic and Social Indicators of Iran 2006.

\begin{tabular}{|c|c|}
\hline Population (millions) & 70.3 \\
\hline Birth per 1000 Pop. & 18 \\
\hline Death per 1000 Pop. & 6 \\
\hline Rate of Natural Increase (\%) & 1.2 \\
\hline Projected Pop. Change $2050(\%)$ & 45 \\
\hline Projected Pop. 2025 (millions) & 89 \\
\hline Projected Pop. 2050 (millions) & 101.9 \\
\hline Infant Mortality Rate & 32 \\
\hline Total Fertility Rate & 2 \\
\hline Percentage of Pop. $<15(\%)$ & 29 \\
\hline Percentage of Pop. $65+(\%)$ & 5 \\
\hline Life Expectancy at Birth (years) & 70 \\
\hline Male Life Expectancy at Birth (years) & 69 \\
\hline Female Life Expectancy at Birth (years) & 72 \\
\hline Percent Urban & 67 \\
\hline $\begin{array}{l}\text { Contraception Use by Women 15-49 (\%) All } \\
\text { Methods }\end{array}$ & 74 \\
\hline $\begin{array}{l}\text { Contraception Use by Women 15-49 (\%) Modem } \\
\text { Methods }\end{array}$ & 56 \\
\hline GNI PPP* per capita, (US \$) 2004 & 8050 \\
\hline Area (square Km.) & $1,648,000$ \\
\hline Density of Pop. (Per square Km.) & 42.7 \\
\hline
\end{tabular}

\section{Conclusion}

Despite of all the merits and demerits of the value of children within the Iranian families, they are a source of synergy and happiness regardless of class, creed, race, community affiliation etc. Based on the analysis conducted on the value of children, social pressures for small families might be increased, if it were commonly known that basic necessities of life became increasingly scarce when some people chose large families. However, the values of children and the resultant happiness cannot be discussed independent of the economic and social conditions. Similarly, change in cultural values have great effects on the value of children, and the government(s) must usually try to change the cultural ideas such as the strong preference for sons to daughters among families. Decisions to have smaller families functionally fit with the historical transition from agricultural societies to industrial ones. In the latter situation, children are more costly to raise, but offer lesser economic returns, which might be more common for both parents to work outside the home. As long as positive values of children outweigh their negative values, parents continue having children as a source of synergy and happiness, apart from the income and support the children supply to their parents in return. Although many leisure pursuits and other means have come to substitute the value of children, children nevertheless prove to be an original source of happiness in the Iranian society. However, mothers continue to play a primary role in bringing prosperity to their children, and the entire process contributes to the happiness within families. Therefore, raising the status of women by empowering them highly affects children's well-being.

\section{Notes}

a) Values are culturally defined standards by which people assess desirability, goodness, and beauty, and which serve as broad guidelines for social living. While people's attitudes may change, society depends more or less on stable values.

b) Cultural transmission is the process by which one generation passes culture to the next (Macionis:1998). The term refers to the process by which accumulated culture has been passed down by both formal and informal methods from generation to generation through learning. It is the inheritance of the ways of acting, thinking, and feeling of a culture.

c) Sociobiology in sociology is known as a theoretical paradigm that explores ways in which the biology of human beings affects their culture. Sociobiology applies to modern evolutionary ideas developed within the biological sciences to the analysis of human behaviour. Sociobiologists assume that human behaviour is conditioned by biological evolution, because traits that have been favoured by selection in the past, will condition our behaviour today.

d) Gender identity refers to traits that females and males, guided by their culture, incorporate into their personalities. Social psychologists treat gender identity as the product of child training rather than as biologically given. 
e) Family violence is defined as the emotional, physical, or sexual abuse of one family member by another. It is also referred to as domestic violence __ a colloquial term referring to the physical abuse of women by their husbands or partners. However, the incidence of and extent to which violence extends is difficult to determine. The interaction assumes that family violence does not exist separately, but practically, it is related to other problems.

\section{References}

1. Croll Elizabeth (2000) Endangered Daughters: Discrimination \& Development in Asia. Routledge, UK, London, p.22.

2. Gittins D (1991) The Family in Question. Macmillan, London, UK, p. 93.

3. Dowrick S, Grundberg S (1980) Why Children. The Women's Press, London, UK, p.12.

4. Salas Rafael M (1985) Reflections on Population. Oxford, Pergamon Press, UK, p.26.

5. Neubeck KJ (1996) Sociology. New York, McGraw- Hill Inc, USA pp.116.

6. Prout A (1990) A New Paradigm for the Sociology of Childhood: Provenance, Promise and Problems. Falmer, London, UK pp.7-34.
7. Montgomery H (2001) Modern Babylon: Prostituting Children in Thailand, Oxford, Berghahn Books.

8. Wulff H (1995) Introducing Youth Culture in its Own Right. Routledge, London, UK, pp.1-18.

9. Jenks M (1996) Childhood. Routledge, London, UK.

10. Goldsmith HH (1983) Genetic Influences on Personality from Infancy. Child Development 54(2): 31-35.

11. UNICEF (2007) The State of the World's Children 2007 United Nations Children's Fund, New York, USA.

12. Mohammad Taghi Sheykhi (1999) Children in focus in Iran: A sociological assessment (JFLSH) Ferdoosi University, Mashhad, Iran 32(1-2): 213.

13. Giant Haim J (1995) Relations Between Parents and Children, (translated by Siavoosh Sartipi into Persian, Tehran, Ettelat Publications. p.158.

14. Macionis JJ (1998) Sociology. Prentice-Hall, London, UK.

15. World Population Data Sheet (2006) Washington DC, Population Reference Bureau, USA.

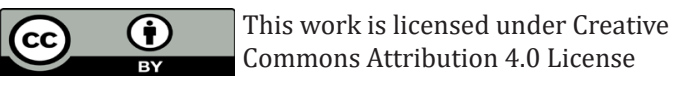

To Submit Your Article Click Here:

Submit Article

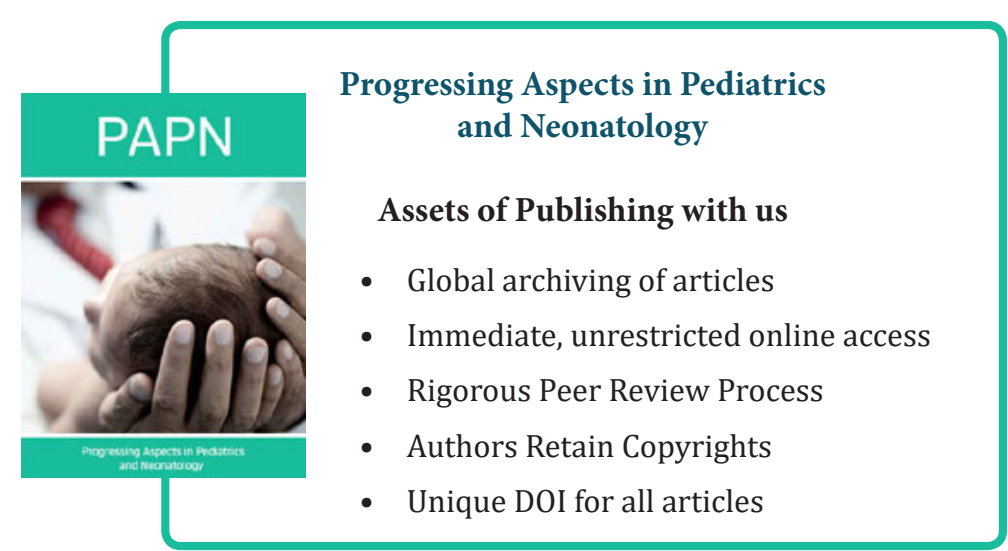

